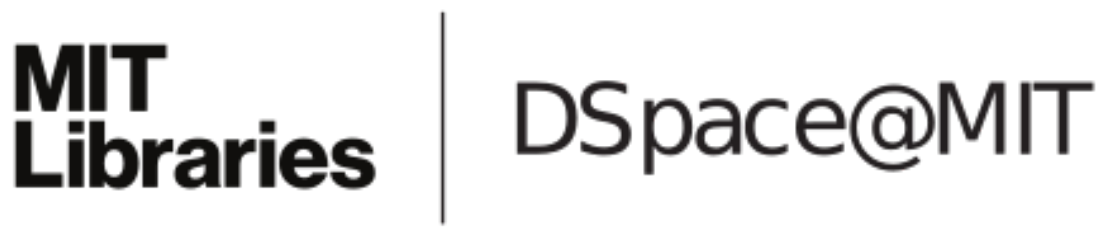

\author{
MIT Open Access Articles
}

\section{Revealing centrality in the spatial structure of cities from human activity patterns}

The MIT Faculty has made this article openly available. Please share how this access benefits you. Your story matters.

Citation: Zhong, C., M. Schlapfer, S. Muller Arisona, M. Batty, C. Ratti, and G. Schmitt. “Revealing Centrality in the Spatial Structure of Cities from Human Activity Patterns." Urban Studies 54 (October 16, 2015), pp. 437-455.

As Published: http://dx.doi.org/10.1177/0042098015601599

Publisher: Sage Publications

Persistent URL: http://hdl.handle.net/1721.1/109118

Version: Author's final manuscript: final author's manuscript post peer review, without publisher's formatting or copy editing

Terms of use: Creative Commons Attribution-Noncommercial-Share Alike 


\title{
Revealing the Changing Spatial Structure of Cities from Human Activity Patterns
}

\author{
Chen Zhong ${ }^{\text {a }}$, Markus Schläpfer ${ }^{\text {b,c,d }}$, Stefan Müller Arisona ${ }^{\text {a,e }}$, Carlo Ratti ${ }^{\text {b,c }}$, \\ Michael Batty ${ }^{\text {f }}$, Gerhard Schmitt ${ }^{\text {a }}$ \\ ${ }^{a}$ Future Cities Laboratory, ETH Zurich, 8092 Zurich, Switzerland \\ ${ }^{\mathrm{b}}$ Senseable City Laboratory, MIT, Cambridge, MA 02139, United States \\ ${ }^{c}$ Singapore-MIT Alliance for Research and Technology, Singapore \\ ${ }^{\mathrm{d}}$ Santa Fe Institute, Santa Fe, NM 87501, United States \\ e Institute of 4D Technologies, University of Applied Sciences and Arts, Northwestern Switzerland \\ FHNW, 5210 Windisch, Switzerland \\ ${ }^{\mathrm{f}}$ Centre for Advanced Spatial Analysis, University College London, 90 Tottenham Court Road, London, \\ W1N 6TR, England
}

\begin{abstract}
Identifying changes in the spatial structure of cities is a prerequisite for the development and validation of adequate planning strategies. Nevertheless, current methods of measurement are becoming ever more challenged by increasingly dispersed forms of urban organisation. Being motivated by the recent availability of large-scale data on human activities, this paper proposes a new quantitative measure for the centrality of locations, taking into account both the number of people attracted to different locations and the diversity of their activities. This 'centrality index' allows for the identification of functional urban centres and for a systematic tracking of their relative importance over time. As a case study, the proposed index is applied to extensive travel survey data in Singapore for the years 1997, 2004 and 2008. It is shown that, on the one hand, the city-state has been developing rapidly towards a polycentric urban form that compares rather closely with the official urban development plan. On the other hand, however, the downtown core has strongly gained in importance, and this can be largely attributed to the extension of the public transit system.
\end{abstract}




\section{Introduction}

Over the last century and a half, many cities have been spreading out, sprawling at much lower population densities and thus growing into vast metropolitan areas. In tandem with this development, the socioeconomic functions of traditional central business districts (CBDs) have been increasingly taken over by a multitude of dispersed and interacting hubs of employment, business and leisure (Anas et al., 1998). Understanding these new 'polycentric' forms of urban organisation is crucial for the development of adequate planning strategies, since the spatial structure exerts strong influence on people's daily life, economic growth, social equity or sustainable urban development (Anas et al., 1998; Horton and Reynolds, 1971; Rodrigue et al., 2009). It is therefore hardly surprising that during recent years the characterisation of urban structure has gained much attention in many scientific fields, ranging from urban geography and regional science to urban economics and spatial planning (Burger and Meijers, 2012; Meijers, 2008; Kloosterman and Lambregts, 2001). Generally, it is agreed that the two most important aspects of urban spatial structure are $i$ ) its morphological dimension, which denotes the size and spatial distribution of intra-urban centres, and ii) its functional dimension, which additionally addresses the linkages between different centres such as the daily flows of commuting or the strength of business and social network connections (Burger and Meijers, 2012; Green, 2007; Vasanen, 2012).

A wide range of analytical methods have been proposed to measure the size and spatial distribution of intra-urban centres from static attributes such as population and employment densities. Greene (1980), for instance, identifies centres using a set of reference thresholds that are derived from local knowledge. The method proposed by (McDonald, 1987) examines the spatial distribution of density functions and considers local peaks as possible sub-centres. A 
parametric method has been proposed using a regression model based on density and distance (McDonald and Prather, 1994), and non-parametric methods have been introduced thereafter based on smoothed density functions (McMillen, 2001; Redfearn, 2007). The main drawbacks of these approaches are the arbitrariness of the chosen population or job density thresholds and the sensitivity of the identified centres to the spatial scale of the analysis (Anas et al., 1998). Another widely applied method for studying the morphological aspect of urban spatial structure is space syntax, which extracts and quantifies the spatial configuration of buildings or the topology of street networks (Hillier, 1996) but this ends to ignore the definition of centres or hubs other than as composed of accessibilities of individual streets.

While still in the development phase, recent work has highlighted the importance of considering the connectivity between centres (Vasanen, 2012). This functional aspect of urban spatial structure has been suggested as playing a key role in the overall performance of an urban system (Burger and Meijers, 2012). Exemplary approaches for measuring functional interdependencies include gravity models to predict the interactions between spatial units based on their size and distance (De Goei et al., 2010; van Oort et al., 2010), the use of network properties to measure connectivity based on people flows (Thiemann et al., 2010), or the concept of connectivity fields to quantify the connection of each centre to the rest of the urban system (Vasanen, 2012).

To examine the relation between the morphological and functional aspect of spatial organisation, a conceptual framework has recently been developed and applied to the urban system in the Netherlands that is known for its polycentric organisation (Burger and Meijers, 2012). The study reveals a strong correlation between morphological and functional Polycentricity, but also shows that functional changes are not necessarily the result of morphological changes. However, it is generally difficult to quantify the differences between 
morphological and functional Polycentricity since these measures are not independent but rather rely on the same definition of what constitutes a city centre.

\subsection{Human Activity Data for Measuring Urban Structure}

Most empirical studies of urban structure have focused on single attributes such as population or employment density for the morphological aspect (Hall and Pain, 2006), and commuting or shopping trips for the functional aspect (Burger and Meijers, 2012). In contrast, the multiplex nature of spatial interactions that combines, for example, trips for commuting, shopping, or leisure, has rarely been studied systematically (Burger et al., 2013). The recent availability of various and large-scale data on human activity now provides unprecedented possibilities to fill this gap and, more generally, to gain new insights in the actual use of urban space. Examples are the identification of urban activities from smart card and related survey data (Ordóñez Medina and Erath, 2013), assessing the function of different regions in a city using floating car and point of interest data (Yuan et al., 2012), or inferring land uses by combining mobile phone records with zoning regulations (Toole et al., 2012). In larger scale, smart card data of individual person movements in the London subway has been analysed to identify the polycentric structure and organization of the city (Roth et al., 2011). Similar research questions have been discussed in (Zhong et al., 2014), quantifying the urban transformation of Singapore with a spatial network model derived from smart card data. Together, these examples demonstrate a clear trend towards directly measuring the real usage and functionality of urban space (Trantopoulos et al., 2011), resulting in a better understanding of the urban dynamics (Schläpfer et al., 2013).

Driven by this new wave of user-generated urban data, this paper proposes a new approach to measure the spatial structure of cities by considering a wide range of different human activities. The clustering of these activities and how they are linked in urban space gives rise to 
a natural definition of functional urban centres that reflect the real usage of places. More specifically, we propose a simple centrality index, which can be applied to large-scale data on human activities. It is demonstrated how this centrality index can be deployed to identify urban centres, to establish functional linkages in space, and to eventually track changes in the overall spatial structure of cities. In this study, detailed travel survey data is used which contains direct information on human activities, but the proposed method is equally well applicable to other types of urban data from which locational activities can be derived.

The remainder of the paper is organised as follows. The next section introduces the proposed centrality index. Section 3 presents a longitudinal case study of Singapore using travel survey data between 1997 and 2008. The empirical results demonstrate the feasibility and value added of the proposed measurement approach. Finally, section 4 concludes the paper with a discussion of the findings.

\section{Measuring the Centrality of Locations}

\subsection{The Theoretical Basis - Applied Central Place Theory}

Central place theory (CPT) emerged in the $19^{\text {th }}$ century in France as part of early location theory but it was formally introduced by Christaller (1933) in empirical terms and theoretically by Lösch (1944). This constitutes the starting point of our proposed method. CPT was originally developed to explain the size and number of towns and cities, together with their distribution in space as a result of economic competition and optimisation principles. The theory is focussed on the inter-urban scale, and is based on the formal idea of a hierarchy of centres that are perfectly nested within one other (Berry and Garrison, 1958). Centres in this hierarchy are differentiated by their size in terms of population and their order in terms of the range of functions that they provide. Accordingly, higher order centres provide more specialised functions (goods and 
services) and thus are characterised by a larger trade area or hinterland from which they draw population. This nestedness implies that higher-order centres embrace all the functions of lowerorder centres plus an additional set of functions that differentiates them from lower-order centres. Empirical studies have shown that such a nested hierarchy is indeed present in real urban systems (Berry and Garrison, 1958). Translating these basic considerations into the context of urban activity and movement data, the two fundamental aspects that determine the importance, or centrality, of a location within a given city are $i$ ) the number of people attracted to different centres, reflecting its size, and ii) the diversity of their activities, reflecting its order. Functional intra-urban centres can then be identified as spatial clusters of locations with a high centrality.

\subsection{A Centrality Index}

The method proposed here quantifies the centrality of a given location by combining the number of people attracted to locations and the range of their activities into a single value called the Centrality Index (CI). Moreover, it provides a smoothed density function that detects spatial clusters of locations with high CI-values. These clusters can be understood as functional centres that shape the overall spatial structure of a city. The calculation of the CI-values consists of the following three steps:

\section{Step 1: Density and Diversity}

Being well-known concepts in the description and analysis of urban form and function, density statistics measure how concentrated human activities are in one spatial unit, while diversity measures how mixed the different kinds of activities are (Cervero and Kockelman, 1997; Mitchell Hess et al., 2001). For our purposes we define density here as the number of distinct people attracted to a given unit area $(x, y)$, normalised by the total number of people visits in the overall $m \times n$ unit space $S$ during a time unit: 


$$
D(x, y)=\frac{N(x, y)}{\sum_{i=1}^{m} \sum_{j=1}^{n} N(i, j)},
$$

where $N(x, y)$ is the number of people visiting unit area $(x, y)$ during a pre-determined time unit. Diversity is represented by entropy which here is a quantitative index that describes the disorder in activities, as originating from information theory (Shannon, 1948). It has long been adopted to measure the degree of complexity and order in a land use arrangement (Kockelman, 1997; Cervero and Kockelman, 1997). Diversity measures the mixing of activity types in one unit area, formulated as:

$$
E(x, y)=-K \sum_{j=1}^{J} P_{j}(x, y) \ln \left(P_{j}(x, y)\right)
$$

where $P_{j}$ is the proportion of travels to cell $(x, y)$ for the activity type $j$ during a given period of time. The constant $K$ is defined as $K=1 / \ln (L)$ with $L$ being the total number of activity types.

\section{Step 2: Ranking Density and Diversity}

Density and diversity are two quantitative values with different dimensions and physical meanings. To integrate them into a single function, we first convert them from absolute values to ranks. The simplest way is to set the rank of the largest density (or entropy) to 1, and then the ranks of all other areas depend on the comparative scale between each of them and the highest ranked area. Another possibility is given from the perspective of probability theory. We assume that the area with highest density (entropy) value implies a maximum probability pf being a higher-order centre, and we thus set its probability to 1 . The probabilities of the other locations are defined by related scales. A formal definition is given as follows. In a two dimensional $m \times n$ space $S$, we denote the density function as $D=\left\{D_{x y}\right\}$, with $x=1,2, \ldots m, y=1,2, \ldots n$, and $D_{x y}$ 
as being the density of cell $(x, \mathrm{y})$ in $S$. For each cell, there will be a function $R_{D}(x, \mathrm{y})=f\left(x, y, D_{x y}\right)$ to denote the probability of a cell to be a city centre based on its density only. Thus, we define the density ranking function as

$$
R_{D}(x, y)=f\left(x, y, D_{x y}\right)=\frac{D_{x y}}{\operatorname{Max}(D)} .
$$

Similarly, $R_{E}(x, y)=g\left(x, y, E_{x y}\right)$ is a probability density function related to diversity $E_{x y}$ at cell $(x, y)$. We define the probability density function of diversity as

$$
R_{E}(x, y)=\mathrm{g}\left(x, y, E_{x y}\right)=\frac{E_{x y}}{\operatorname{Max}(E)} .
$$

Density and diversity are two complementary indices referring to the spatial distribution of activities. None of them can fully represent central areas individually, especially in the context of modern cities, where mono-functional areas exist. For instance, a residential district might have very high density but a limited number of activity types, which should be differentiated for multi-functional centres. Moreover, as shown in Figure 1 (top), there could be two areas having the same level of diversity but very different densities. Figure 1 (bottom) shows that there could be some non-central areas with high diversity of activity types yet with only a small number of people visiting. The proposed centrality index considers both locational characteristics by integrating them into a single value. 


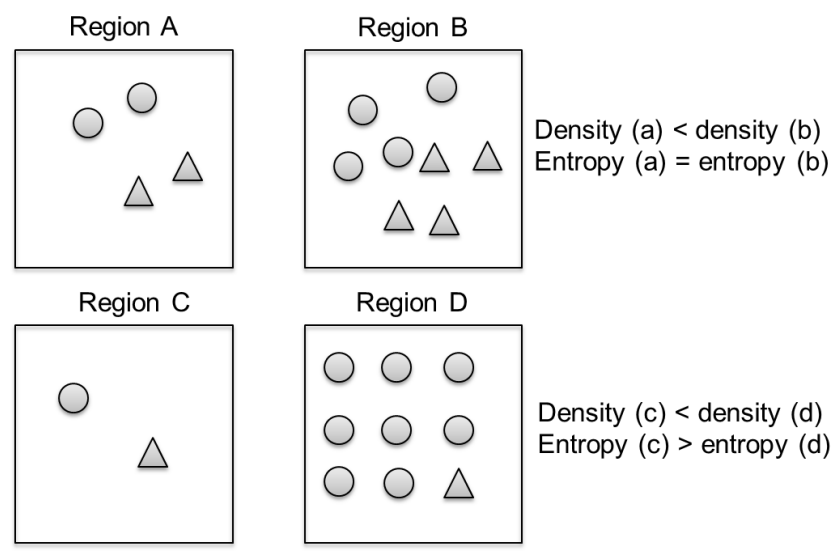

Figure 1. Difference between density and diversity of activities in a given location. Circles and triangles represent two different types of activities.

\section{Step 3: Computing Centrality by Convolution-Based Smoothing}

The centrality index, $C(x, y)$, measures the centrality of an area $(x, y)$ in a city. It is the possibility of the area being a centre, derived by combining the density of people and the diversity of their activities through the spatial convolution function:

$$
C(x, y)=R_{D}(x, y) * R_{E}(x, y) .
$$

Convolution is a fundamental concept in signal processing and analysis (Young et al., 1998).

Generally, given two time-dependent functions $f_{1}(t)$ and $f_{2}(t)$, their convolution is calculated as:

$$
f(t)=\int_{-\infty}^{+\infty} f_{1}(\tau) f_{2}(t-\tau) d \tau
$$

being often denoted as $f(t)=f_{1}(t) * f_{2}(t)$. 
If the two functions are based on a spatial variables like $x, y$ rather than based on time, we call it a spatial convolution. As such, equation (5) is a discrete 2D spatial convolution to "add" the variables $R_{D}$ and $R_{E}$, see also Figure 2. At each cell $(x, y)$ in the output function, we place two $3 \times 3$ windows. These windows cover 9 cells with $R_{D}$ and $R_{E}$ individually. $C_{x y}$ is the sum of the 9 multiplications. Thus, the result of the convolution operation is twofold: (1) Two dimensions are reduced to a single index, which is then used to delineate urban centres by a customized ranking and (2) areas with opposed density and entropy values are "filtered out".

\begin{tabular}{|c|c|c|c|c|c|c|}
\hline $\begin{array}{c}R_{E}(x-1, \\
y+1)\end{array}$ & $\begin{array}{c}R_{E}(x, y \\
+1)\end{array}$ & $\begin{array}{c}R_{E}(x+1, \\
y+1)\end{array}$ & $\begin{array}{c}R_{D}(x-1, \\
y+1)\end{array}$ & $\begin{array}{c}R_{D}(x, y \\
\quad+1)\end{array}$ & $\begin{array}{c}R_{D}(x+1, \\
y+1)\end{array}$ & \\
\hline $\begin{array}{c}R_{E}(x-1, \\
y)\end{array}$ & $R_{E}(x, y)$ & $\begin{array}{c}R_{E}(x+1, \\
y)\end{array}$ & $\begin{array}{c}R_{D}(x-1, \\
y)\end{array}$ & $R_{D}(x, y)$ & $\begin{array}{c}R_{D}(x+1, \\
y)\end{array}$ & $C(x, y)$ \\
\hline $\begin{array}{c}R_{E}(x-1, \\
y-1)\end{array}$ & $\begin{array}{l}R_{E}(x, y- \\
\text { 1) }\end{array}$ & $\begin{array}{c}R_{E}(x+1, \\
y-1)\end{array}$ & $\begin{array}{c}R_{D}(x-1, \\
y-1)\end{array}$ & $\begin{array}{c}R_{D}(x, y- \\
\text { 1) }\end{array}$ & $\begin{array}{c}R_{D}(x+1, \\
y-1)\end{array}$ & \\
\hline
\end{tabular}

Figure 2. Spatial convolution with contiguity edges and corners.

\section{A Case Study: Changing Spatial Structure of Singapore}

\subsection{Urban Planning in Singapore}

Singapore is an island city-state in Southeast Asia with an area of $710.2 \mathrm{~km}^{2}$. Its population including non-residents was approximately 5.4 million in 2013, 4.6 million in 2007, 4.2 million in 2004, and 3.7 million in 1997 according to national statistics ${ }^{1}$. Hence, the total population today has grown by about $30 \%$ compared to its population one decade ago. From the 19th century and the first half of the 20th century, Singapore's physical growth was rather haphazard and largely unregulated. It was only in the mid-1950s that Singapore began to implement its

\footnotetext{
${ }^{1}$ Singapore National Statistics http://www.singstat.gov.sg/ accessed 26/05/14
} 
first concept plan, which has had far-reaching impacts on its urban spatial structure. The revised concept plan $^{2}$ of 1991 emphasised sustainable economic growth, and proposed the idea of decentralisation. It is also one of the most influential plans that shaped the structure of Singapore. The CBD was planned to be surrounded by several regional centres, sub-regional centres, and fringe centres, see Figure 3. The idea behind this urban plan was to bring jobs closer to the homes and to relieve congestion in old central areas.

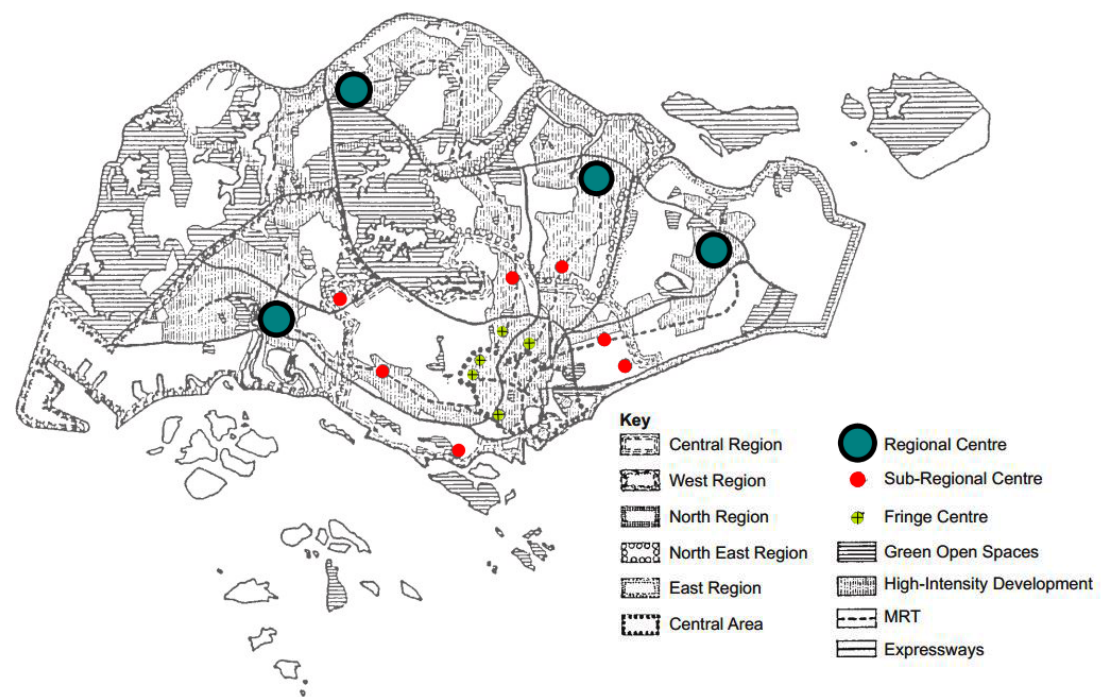

Figure 3. The revised concept plan of 1991, image recreated from (Field, 1999).

\subsection{Data Processing}

Extensive travel survey data, the so-called Household Interview Travel Survey (HITS), is used for the present study case. The survey is conducted by the Singapore Land Transport Authority (LTA) every four to five years to provide transport planners and policy makers with insights into travelling behaviours. About $1 \%$ of households in Singapore are surveyed, with household members answering detailed questions about their trips. The HITS data provide comprehensive

\footnotetext{
${ }^{2}$ Singapore Concept Plan https://www.ura.gov.sg/uol/concept-plan.aspx?p1=View-ConceptPlan\&p2=Concept-Plan1991 accessed 26/05/14
} 
information such as age, occupation, travel purpose, travel destination or travelling time. A detailed description of HITS data can be found in (Cheong and Toh, 2010).

To compare the urban spatial structure of different years, we use the HITS data of 1997 , 2004 and 2008, which contain 48,881, 51,000 and 76,923 records after data processing. These data originally have different classifications of activity types for each year, see Table 1 . Thus, to get a unified base of classification for the different years, an aggregation has to be conducted resulting in a total of 9 aggregated activity categories. The number of trips for each aggregated activity are given in Table 2 .

With these available data sets, we test the feasibility of our approach by measuring the urban development process of Singapore over the studied period. The results are discussed in two parts. The first part shows the relationships between diversity, density and the resulting centrality indices. The second part examines the changes in the spatial structure over the different years and compares them with the official urban plan. 
Table 1. Original activity types versus aggregated activity types.

\begin{tabular}{|c|c|c|c|}
\hline \multirow[b]{2}{*}{ Categories } & \multicolumn{3}{|c|}{ Year } \\
\hline & 1997 & 2004 & 2008 \\
\hline 1 & Going home & Go home & Return home \\
\hline 2 & Going to school & Go to school & Education \\
\hline 3 & Going to work place & Go to workplace & Go to work \\
\hline 4 & Part of work & $\begin{array}{l}\text { Part of work (Traveling } \\
\text { on business) }\end{array}$ & Work-related business \\
\hline 5 & Shopping & Shopping & Shopping \\
\hline 6 & Eating & Eating & Meal / eating break \\
\hline 7 & Social & Social & Social visit/gathering/religion \\
\hline \multirow[t]{3}{*}{8} & Recreation & Recreation & Recreation \\
\hline & & & Entertainment \\
\hline & & & Sports/exercise \\
\hline \multirow[t]{4}{*}{9} & Others & For some other reason & Others \\
\hline & Serve Passenger & $\begin{array}{l}\text { Serve Passenger } \\
\text { (e.g.: pick up / drop off } \\
\text { passenger) }\end{array}$ & To drop-off/pick-up someone \\
\hline & Personal business & $\begin{array}{l}\text { Personal business } \\
\text { (e.g.: visit doctor, bank) }\end{array}$ & $\begin{array}{l}\text { Personal errand/task (pay } \\
\text { bill/banking) } \\
\text { Medical/dental (self) }\end{array}$ \\
\hline & & & To accompany someone \\
\hline
\end{tabular}


Table 2. Number of trips broken down into the aggregated categories for each year

\begin{tabular}{lrrr} 
& \multicolumn{3}{c}{ Year } \\
\cline { 2 - 4 } Categories & 1997 & 2004 & 2008 \\
\cline { 2 - 4 } & 21100 & 23543 & 34314 \\
2 & 3177 & 7498 & 9757 \\
3 & 8407 & 10425 & 18310 \\
4 & 1166 & 736 & 1453 \\
5 & 3511 & 2372 & 2239 \\
6 & 2966 & 830 & 1634 \\
7 & 1768 & 1115 & 2108 \\
8 & 1212 & 267 & 767 \\
9 & 5574 & 4123 & 6341 \\
Valid records in total & 48881 & 50909 & 76923 \\
Original records in total & 52801 & 60917 & 88601 \\
\hline
\end{tabular}

\subsection{Density, Diversity and Centrality}

In our case study, we use 24 hours as the temporal unit since the survey is a report of people's activity in one day. We use a grid cell size of $500 \times 500$ meters to partition the entire city area into a rectangular square grid of 3578 cells. Note that the chosen size of the grid cells approximately corresponds to the average walking distance to transportation infrastructure according to (van Eggermond et al., 2012). To avoid side effects of geocoding, a mean filter of entropy and density is used, replacing each density/entropy value of a cell with the mean (average) value of its neighbours (with contiguity edges and corners) including the cell itself. By smoothing the values in this way, cell values that are not representative of their surroundings can be "eliminated". To assess the influence of this smoothing function, we compared the 
centrality values to those generated without such process. The results reveal qualitatively similar trends.

The results of diversity, density, and centrality are shown in Figure 4. As indicated, there are some locations with highly opposed density and diversity patterns. An example is the area around Jurong West, which is known to be mostly occupied by residential blocks with some schools. Consequently, as confirmed in Figure 4, Jurong West is characterised by a high density but a low diversity, resulting in relatively low CI-values after the spatial convolution. More examples are provided in Figure 5, showing the relation between density and diversity for each grid cell. Though the correlation between the two dimensions is very high $(r>0.5$, see Table 3$)$, there are some clear exceptions. The selected dots in Figure 5 correspond to areas in the northeast of Singapore (the Hougang area) which has comparatively high density but lower diversity of the human activities. Because residential buildings dominate the land-use in that area, the spatial convolution reduces the CI-values into lower level bins as shown in the histogram of Figure 5. Note that the development path in this area is also characterised by an increase of the centrality values between 1997 and 2004, followed by a decrease between 2004 and 2008, see below in Figure 7. This changing activity patterns might be rooted in a continuous development of new neighbourhoods in the area in the 1990s, but the opening of a rapid transit lines in 2000s has led again to an outflow of people. 

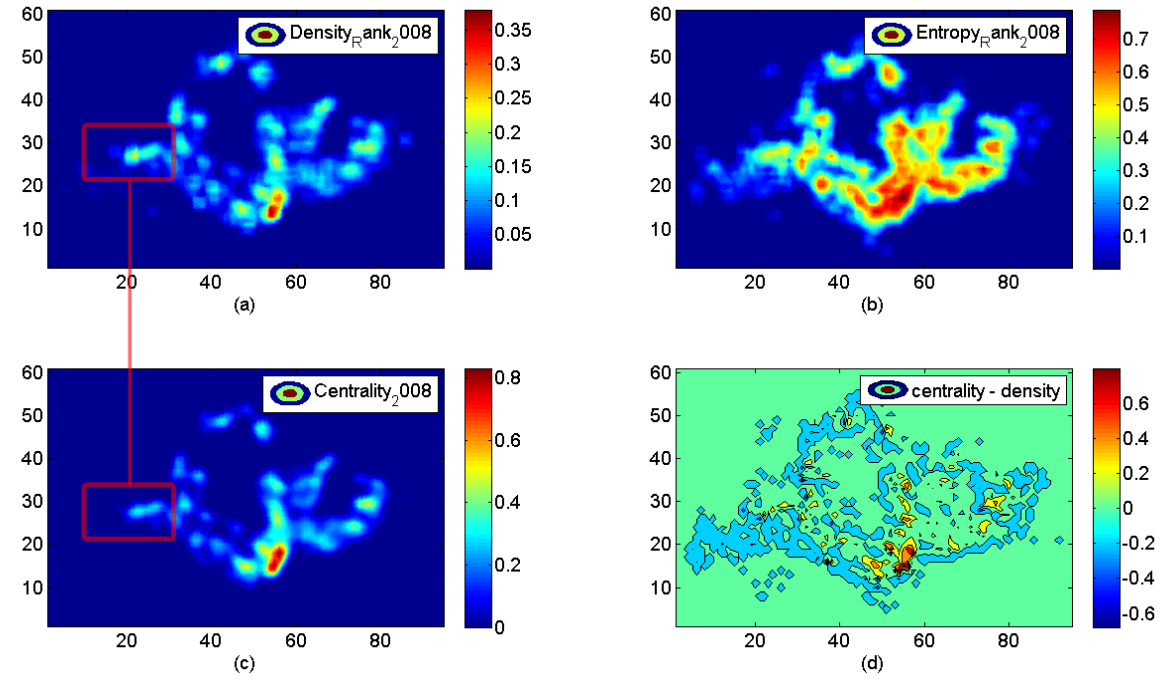

Figure 4. (a) Density of urban activities. (b) Diversity of urban activities. (c) Centrality values. (d) Difference between centrality and density to assess the functionality of convolution. $x, y$ axis represent the index of the geographical coordinates system of Singapore.

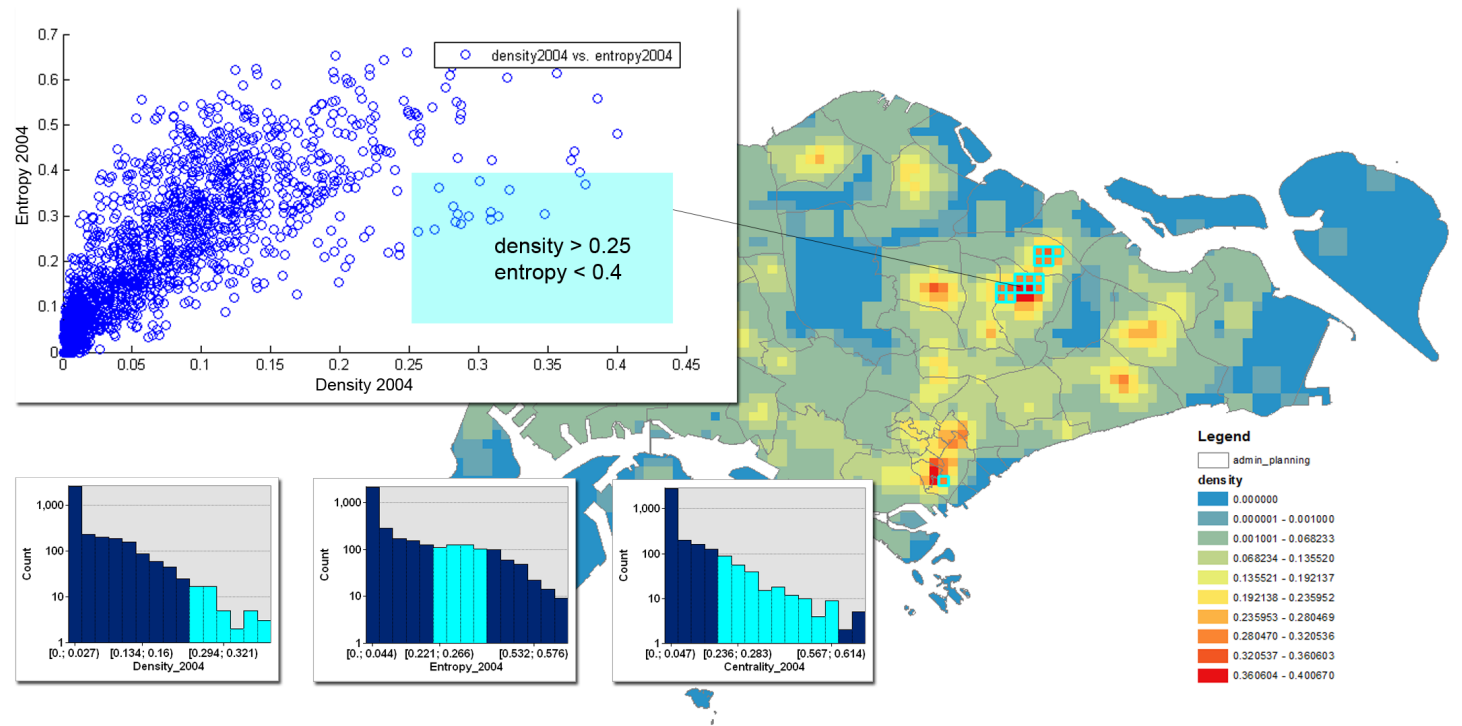

Figure 5. Density and diversity (entropy) patterns. The density and diversity values for 2004 are plotted (left). We selected a number of cells with comparatively high density but low entropy. As demonstrated, the selected dots correspond to areas in the northeast of Singapore. 


\subsection{Polycentric Urban Transformation}

In this section, the statistical and spatial distributions of centres are compared for the different years from three perspectives: (1) the overall value of centrality - how Singapore develops in general? (2) the balance of the distribution - where are the centres? And (3) anomalous developments - are there any local developments against the general trends identified in (1)? A histogram indicating the number of locations with a given CI-value is given in Figure 6, while the corresponding geographical mapping is provided in Figure 7.

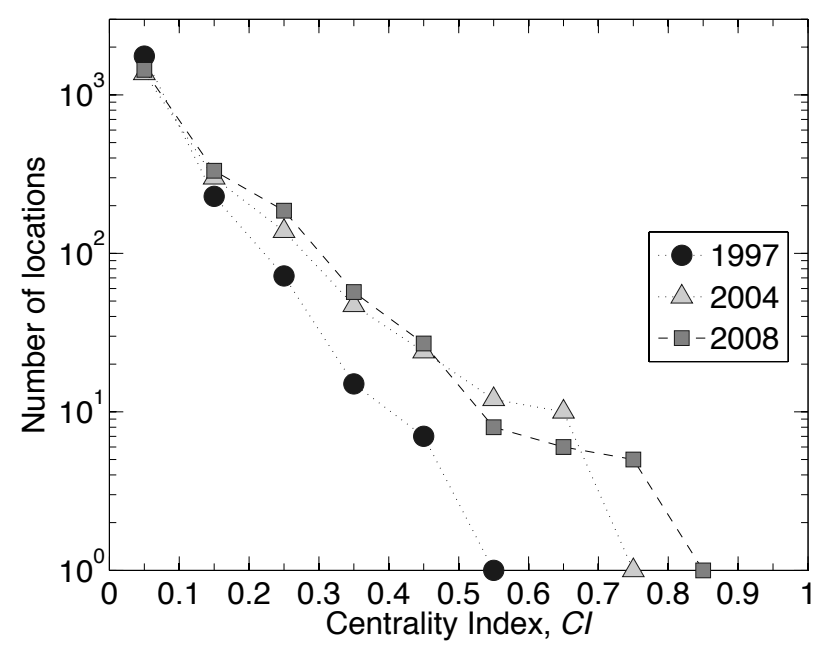

Figure 6. Histogram indicating the number of locations with a given $\mathrm{Cl}$-value for the studied years.

\section{(1) The overall value of centrality}

During the last five decades as an independent city-state, Singapore has experienced rapid urban development and transformed itself from a declining trading post to a First World economy (Huat, 2011). It is therefore not surprising that the average centrality increased during the observation period of this study (see Table 3), implying that the city has become more 'active' in general. This change can be also captured from the geographical map (Figure 7) 
where areas with medium centrality values $(0.1<\mathrm{CI}<0.3)$ have became more dispersed. At the same time, the number of grid cells with high CI-values $(\mathrm{CI}>0.3)$ has substantially increased (Figure 6 and Table 3), indicating a significant increase in the number of central hubs between 1997 and 2004. The histogram in Figure 6 also shows evidence of high heterogeneity in locations with respect to their centrality. Simply put, most locations are visited by just a few people and for similar reasons, while a few central 'hubs' attract a huge part of Singapore's population for many different reasons.

\section{(2) Balance of the distribution}

We define a functional centre as a cluster of adjacent cells that have the same minimum centrality value. As indicated in Table 3 the number of these clusters also increased. Inspecting the geographic mapping in Figure 7 we can see that the location and clustering of high-CI cells has changed between 1997 and 2008. For instance, the three intra-urban centres Jurong in the west, Tampines in the east and Woodlands in the north were gradually growing into regional centres with similar centrality values. Comparing the centrality map in 2004 and 2008 shows that the CI-values in the Hougang area decreased, while those of the centres in the western part of Singapore slightly increased. This suggests a development trend towards more evenly distributed centres in space.

The results discussed so far correspond well to Singapore's official planning concept (see Figure 3). However, the study also reveals that other emerging sub-centres like the ones in Yishun and Bedok have higher relative CI-values than anticipated in the official plans. To some extent, this may show evidence of bottom-up and thus hard-to-predict changes that have been suggested to shape the urban spatial structure well beyond classic top-down planning.

The standard deviations of both density and diversity increased in 2004 and decreased again in 2008, which indicates that the distribution of activity became more uneven in 2004 . The western region of Singapore - the Jurong East area was mainly occupied by industry, and the 
blueprint to transform the Jurong Lake district into unique lakeside destinations for business and leisure was unveiled only in recent years.

\section{(3) Anomalous developments}

To further quantify the spatial clustering of locations with high CI-values we calculated the global spatial autocorrelation in terms of Moran's I index (Moran, 1950). As reported in Table 3 , this value is increasing throughout the analysis years, suggesting (1) a strong spatial clustering of high centrality areas and (2) an increasing difference of centrality between distinct areas. The second point is in line with an increasing standard deviation of the overall centrality values (see Table 3). Thereby, the numbers of cells that form the biggest centre in the southern part of Singapore (CBD) were increasing, see Figure 7. This area was planned as a CBD already in the earliest urban plans. The impact of this original plan is still obvious today. The downtown core keeps on growing since the development of this area had high priorities in the urban plans that promote its economic development. In addition this the growth is influenced by the recent development of the public transit system. The rapid transit system was built to substantially shorten the travel time from essentially everywhere on the island to the CBD which, on average, leads to increased travel distance. The growing importance of the downtown core can thus be seen as a contra development against the general trend towards decentralization in Singapore. The increasing average travel distance but slightly changed travel time seem to further support this result, see Table 3 . 

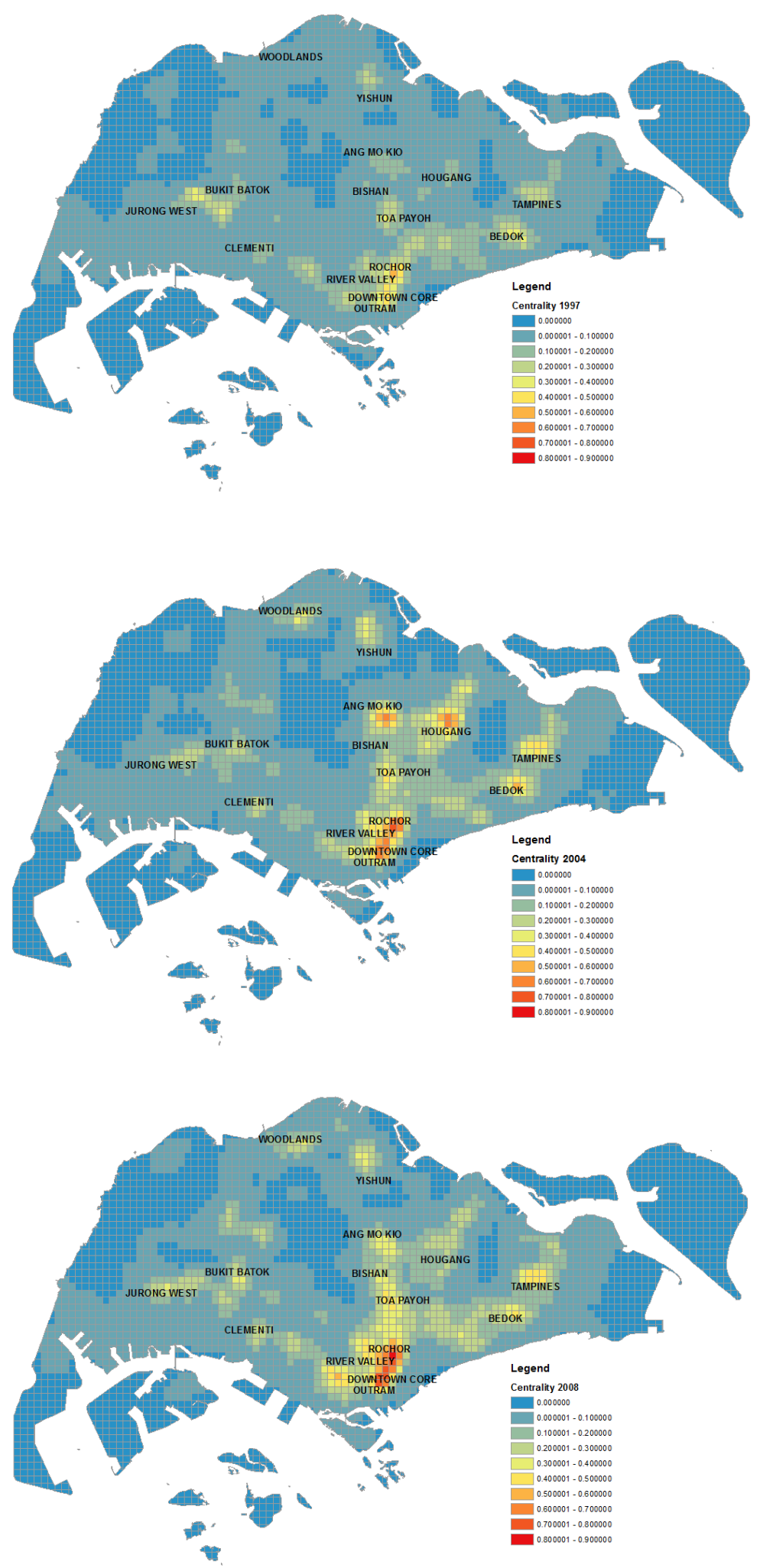

Figure 7. Centrality maps generated from the HITS travel survey for the years 1997,2004 , and 2008. 
Table 3. A comparison of attributes of centres with data of 1997, 2004, and 2008.

\begin{tabular}{|c|c|c|c|}
\hline \multirow[b]{2}{*}{ Indices } & \multicolumn{3}{|c|}{ Year } \\
\hline & 1997 & 2004 & 2008 \\
\hline Avg. Centrality & 0.024611 & 0.039981 & 0.04654 \\
\hline Max. Centrality & 0.54349 & 0.7083 & 0.83775 \\
\hline Standard_deviation_centrality & 0.056668 & 0.090856 & 0.095621 \\
\hline Moran I index & 0.739429 & 0.744428 & 0.776470 \\
\hline Max. density & 0.0185 & 0.0085 & 0.0091 \\
\hline Standard_deviation_density & 0.0008 & 0.0007 & 0.0006 \\
\hline Moran I index & 0.725631 & 0.76267 & 0.759729 \\
\hline Avg. entropy & 0.2912 & 0.2133 & 0.2763 \\
\hline Max. entropy & 2.0347 & 2.1274 & 1.9653 \\
\hline Standard_deviation_entropy & 0.5160 & 0.4243 & 0.4798 \\
\hline Moran I index & 0.856524 & 0.838281 & 0.859153 \\
\hline Density\&entropy & 0.5668 & 0.6925 & 0.6280 \\
\hline \multicolumn{4}{|l|}{ Correlation coefficients } \\
\hline Number of grid cells with centrality $>0.3$ & 23 & 94 & 104 \\
\hline Number of centres $>0.3$ & 5 & 10 & 10 \\
\hline Number of grid cells with centrality $>0.7$ & 0 & 1 & 6 \\
\hline Number of centres $>0.7$ & 0 & 1 & 1 \\
\hline Avg. Travel distance (meters) & 6679.024795 & 6025.103026 & 7198.035154 \\
\hline \multicolumn{4}{|l|}{ (point to point distance) } \\
\hline Avg. in vehicle Time (walking excluded) & NA. & 20.5173 & 21.2826 \\
\hline Avg. Travel distance for working (meter) & NA. & 8233.49551 & 9143.759983 \\
\hline Avg. Travel distance for shopping (meter) & NA. & 4790.603066 & 6044.536754 \\
\hline Avg. Travel distance to school (meter) & NA. & 3697.089502 & 4933.560101 \\
\hline Avg. Travel distance for eating (meter) & NA. & 3829.186409 & 5135.631026 \\
\hline
\end{tabular}




\section{Conclusions}

Quantitative measures for the spatial structure of cities have the potential to greatly contribute to a better understanding and management of urban transformation processes. By rethinking the recent debates about Polycentricity and motivated by the growing availability of human activity data, this paper has proposed a new measure of locational centrality. A simple quantitative index is calculated by combing density and diversity of human activities. Subsequently, centres of urban activities can be identified as spatial clusters of locations with high centrality, allowing to assess the spatial distribution of centres over different years and to trace urban transformation processes. Taking Singapore as a case study area, we used longitudinal travel survey data to demonstrate the effectiveness of the proposed measurement method. The quantitative approach and the results can be used as references for more explicitly interpreting and representing urban changes, eventually allowing to inform urban planning applications.

Further research is needed to fully explore the potential applications of the proposed methodology. First, the usage of these indices are not limited to travel survey data, for they can be applied to other human mobility data sets with a higher spatiotemporal resolution, such as mobile phone records or smart card data. Second, the indices can be used not only for detecting urban activity centres but can also be further extended for detecting specific functional centres, such as education or shopping centres. Finally, it should be noted that the specific ranking functions we defined here are based on the idea that intra-urban centres are characterised by both high density and high diversity of activities. These functions could be further refined within our proposed framework by integrating local expert knowledge, so as to uncover urban problems and better explain urban phenomena 


\section{Acknowledgment}

This research cooperation was established at the Singapore-ETH Centre (SEC) and the Singapore-MIT Alliance for Research and Technology (SMART), co-funded by the Singapore National Research Foundation (NRF) and ETH Zurich. The authors would like to express their sincere gratitude to the Singapore Land Transport Authority and Urban Redevelopment Authority for supporting this research and providing the required data. 


\section{References}

Anas A, Arnott R and Small KA. (1998) Urban spatial structure. Journal of economic literature 36(3): 1426-1464.

Berry BJ and Garrison WL. (1958) Recent developments of central place theory. Papers in Regional Science 4(1): 107-120.

Burger M and Meijers E. (2012) Form follows function? Linking morphological and functional polycentricity. Urban Studies 49(5): 1127-1149.

Burger MJ, van der Knaap B and Wall RS. (2013) Polycentricity and the multiplexity of urban networks. European Planning Studies (ahead-of-print): 1-25.

Cervero R and Kockelman K. (1997) Travel demand and the 3Ds: Density, diversity, and design. Transportation Research Part D: Transport and Environment 2(3): 199-219.

Cheong CC and Toh R. (2010) Household interview surveys from 1997 to 2008-A decade of changing travel behaviours. Editorial Team: 52.

Christaller W. (1933) Central Places in Southern Germany. Translation into English by Carlisle W. Baskin in 1966. Englewood Cliffs, NJ: Prentice-Hall.

De Goei B, Burger MJ, Van Oort FG and Kitson M. (2010) Functional polycentrism and urban network development in the Greater South East, United Kingdom: evidence from commuting patterns, 1981-2001. Regional Studies 44(9): 1149-1170.

Field BG. (1999) The morphology of planning in an urban laboratory. Property Management 17(2): 139156.

Green N. (2007) Functional polycentricity: a formal definition in terms of social network analysis. Urban Studies 44(11): 2077-2103.

Greene DL. (1980) Recent trends in urban spatial structure. Growth and Change 11(1): 29-40.

Hall PG and Pain K. (2006) The polycentric metropolis: learning from mega-city regions in Europe: Routledge.

Hillier B. (1996) Space is the machine: a configurational theory of architecture, Cambridge, UK: Cambridge University Press.

Horton FE and Reynolds DR. (1971) Effects of urban spatial structure on individual behavior. Economic Geography 47(1): 36-48.

Huat CB. (2011) Singapore as Model: Planning Innovations, Knowledge Experts. Worlding Cities. Wiley-Blackwell, 27-54.

Kloosterman RC and Lambregts B. (2001) Clustering of economic activities in polycentric urban regions: the case of the Randstad. Urban Studies 38(4): 717-732.

Kockelman KM. (1997) Travel behavior as function of accessibility, land use mixing, and land use balance: evidence from San Francisco Bay Area. Transportation Research Record: Journal of the Transportation Research Board 1607(1): 116-125.

Lösch A. (1944) Die räumliche ordnung der wirtschaft: Verlag von Gustav Fischer.

McDonald JF. (1987) The identification of urban employment subcenters. Journal of Urban Economics 21(2): 242-258.

McDonald JF and Prather PJ. (1994) Suburban employment centres: the case of Chicago. Urban Studies 31(2): 201-218.

McMillen DP. (2001) Nonparametric employment subcenter identification. Journal of Urban Economics 50(3): 448-473.

Meijers E. (2008) Measuring polycentricity and its promises. European Planning Studies 16(9): 13131323.

Mitchell Hess P, Vernez Moudon A and Logsdon MG. (2001) Measuring land use patterns for transportation research. Transportation Research Record: Journal of the Transportation Research Board 1780(1): 17-24.

Moran PA. (1950) Notes on continuous stochastic phenomena. Biometrika 37(1/2): 17-23.

Ordóñez Medina A and Erath A. (2013) Estimating dynamic workplace capacities using public transport smart card data and a household travel survey. presented at Transportation Research Board (TRB) 92nd Annual Meeting. Washington, D. C. 
Redfearn CL. (2007) The topography of metropolitan employment: Identifying centers of employment in a polycentric urban area. Journal of Urban Economics 61(3): 519-541.

Rodrigue J-P, Comtois C and Slack B. (2009) The geography of transport systems, London: Routledge.

Roth C, Kang SM, Batty M and Barthélemy M. (2011) Structure of urban movements: polycentric activity and entangled hierarchical flows. PloS one 6(1): e15923.

Schläpfer M, Bettencourt L, Grauwin S, Raschke M, Claxton R, Smoreda Z, West G B and Ratti C. (2013) The scaling of human interactions with city size. Available online at: http://arxiv.org/abs/1210.5215.

Shannon CE. (1948) A mathematical theory of communication. Bell System Technical Journal 27(3): 379-423.

Thiemann C, Theis F, Grady D, Brune R and Brockmann D. (2010) The structure of borders in a small world. PloS one 5(11): e15422.

Trantopoulos K, Schläpfer M and Helbing D. (2011) Toward sustainability of complex urban systems through techno-social reality mining. Environmental Science \& Technology 45: 6231-6232.

Toole JL, Ulm M, González MC and Bauer D. (2012) Inferring land use from mobile phone activity. Proceedings of the ACM SIGKDD International Workshop on Urban Computing. 1-8.

van Eggermond M, Erath A and Axhausen KW. (2012) Vehicle ownership in Singapore using revealed preference data and spatial measures. Proceedings of the 13th International Conference on Travel Behaviour Research, Toronto, Canada.

van Oort F, Burger M and Raspe O. (2010) On the economic foundation of the urban network paradigm: spatial integration, functional integration and economic complementarities within the Dutch Randstad. Urban Studies 47(4): 725-748.

Vasanen A. (2012) Functional polycentricity: examining metropolitan spatial structure through the connectivity of urban sub-centres. Urban Studies 49(16): 3627-3644.

Young IT, Gerbrands JJ and Van Vliet LJ. (1998) Fundamentals of image processing: Delft University of Technology Delft, The Netherlands.

Yuan J, Zheng Y and Xie X. (2012) Discovering regions of different functions in a city using human mobility and POIs. Proceedings of the 18th ACM SIGKDD international conference on Knowledge discovery and data mining. Beijing, China: ACM, 186-194.

Zhong C, Arisona SM, Huang X, Batty M and Schmitt G. (2014) Detecting the dynamics of urban structure through spatial network analysis. International Journal of Geographical Information Science (ahead-of-print): 1-22. 
Appendix

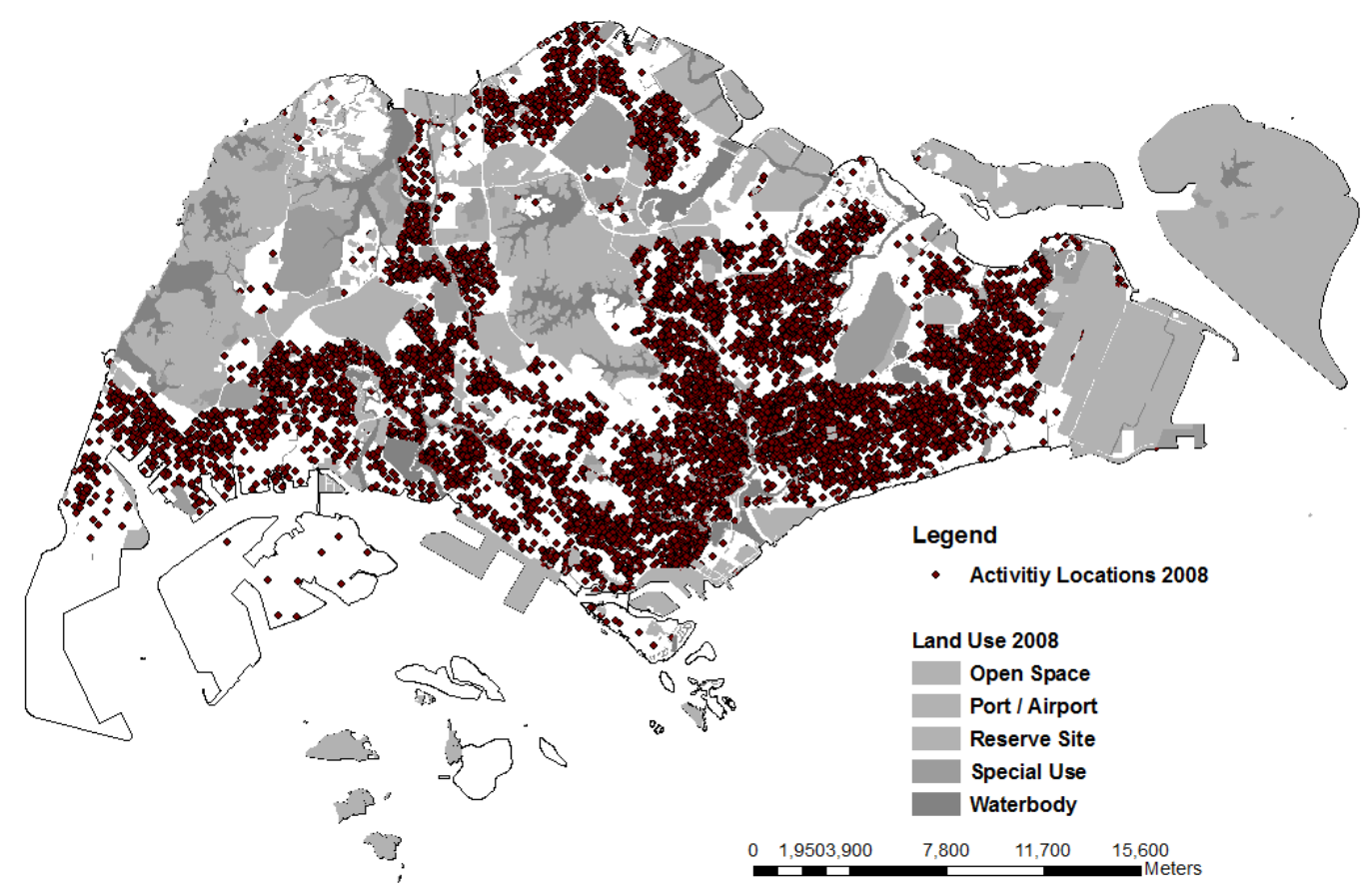

Figure A.1. Case study area - Singapore. Activity locations are arrival locations of trips in HITS 2008. The areas which barely have any activity points are mainly open space, port, reserve site, special used areas, and water body according to the master plan 2008. 